\title{
Business Models at Work in the Mobile Service Sector
}

\author{
Jeaneth Johansson, Malin Malmström, Diana Chroneer, Maria Ek Styven, Anne Engström, \\ Birgitta Bergvall-Kåreborn
}

Luleå University of Technology, Luleå, Sweden.

Email: Jeaneth.Johansson@ltu.se

Received November $28^{\text {th }}, 2011$; revised December $30^{\text {th }}, 2011$; accepted January $12^{\text {th }}, 2012$

\begin{abstract}
This paper aims to enhance the knowledge of business models in the mobile service sector by exploring their key mechanisms and underlying components. By combining the business model literature with empirical interview-based case studies of 69 business models in the mobile service sector, it illustrates the findings of a longitudinal case study of a business model design attached to an iPhone application. A model for managing business model design in an open innovation context of mobile services is proposed. The model extends earlier frameworks by adding contingency aspects and the view of core resources for addressing logics in the dynamic sector. Findings highlight the importance of ventures in the mobile service sector continually managing the business model design in order to support the sustainability of their business models.
\end{abstract}

Keywords: Business Model; Open Innovation; Mobile Service; Mobile Application; iPhone; Resources

\section{Introduction}

In the last few decades, new market conditions and technological advances have not only contributed to an increasing number of ventures being international from their inception, or being "born global" [1], but also to a dynamic environment that challenges traditional views on ventures' business models. As the Internet and related technologies have changed the way business is done, interest in business models has grown among managers and scholars. There has been a proliferation of e-business models that are based on different logics from traditional businesses [2]. But for ventures launching business models linked to a more open innovation context of the Internet, the nature of business model logics is still in its infancy. This has caused an uncertainty in the business model design and management. Research in the service sciences also indicates the need to develop sustainable business models [3].

For these reasons, understanding and designing business models has become highly important in the new and rapidly evolving mobile services sector. Today's mobile service environment has been compared to the early stages of the wired Web [4] in terms of its fragmented network, applications, and device platforms [5]. Moreover, ventures in the mobile service sector are working increasingly in value networks, where mobile services are developed and provided by networks of cooperating ventures.

This move towards value networks also implies a transition from closed to open innovation, meaning that in- novations can move easily between the venture and its environment. Research indicates that new business models are of central importance in open innovation [6]. In the mobile service sector, the logic behind open innovation is that anyone can develop a service anytime and reach anywhere; the service is born global.

The objective of this paper is to enhance the knowledge of business models in the mobile service sector by exploring its key mechanisms and underlying components. This will be achieved by answering the following exploratory questions: What are the key mechanisms and underlying business model components? How do these interact in a business model design?

Drawing from the business model literature and from empirical case studies on 69 business models in the mobile service sector, the paper illustrates the findings of a longitudinal case study of a business model linked to development of an iPhone application. We develop a model for business model design for mobile services in an open innovation context. The proposed model extends earlier frameworks by identifying and incorporating the key mechanisms; contingency aspects and core resources in a dynamic sector. Conclusions based on the model and empirical data are provided, as are suggestions for future research. This study contributes to the research on business models and service science by exploring business model design at work within the nascent research field of mobile services. 


\section{Literature Review}

In the last few decades, business model design has attracted the attention of both scholars and practitioners. However, trends of open innovations in services, such as shifting from product to service and customer empowerment in innovation [7] have been neglected in conceptual research on business model definitions, nature and structure [8]. Generally speaking, business models define the logic of the firm and reflect its business strategy. Business model research has lately changed in focus and approach, to emphasize components rather than specific models or typologies [9], as this provides a better understanding of how and where value is created and captured. In their synthesis of business model literature, which included established publications from 1998 to 2002, Shafer et al. [10] uncovered 12 business model definitions comprising 42 business model components. Four categories of components were identified: strategic choices, creating value, capturing value, and value network. The authors define a business model as “a representation of a venture's underlying core logic and strategic choices for creating and capturing value within a value network” (p. 202). There is, however, a lack of empirical support for conceptually developed business models.

Several studies have synthesized previous work in the area of business model components. Based on such a synthesis, Morris et al. [11] propose a business model framework that includes factors related to the offering, market factors, internal strategy factors, competitive strategy factors, economic factors, and personal/investor factors. According to Morris et al., their framework is not sectorspecific and could thus be used to design, describe, categorize, critique, and analyze a business model for any venture. Nevertheless, there is a need to acknowledge the sector-specific and venture-specific characteristics of business models.

A review of the business model literature by Osterwalder et al. [9], results in a proposed framework with nine "business model building blocks": value proposition, target customer, distribution channel, relationship, value configuration, core competency, partner network, cost structure, and revenue model. Their framework incorporates the venture's internal parts of the business model. The internal parts as proposed by Osterwalder et al. [9] however need to fit an open innovation context where internal and external parts interact without boundaries.

Chesbrough and Rosenbloom [12], propose six functions of a business model (Table 1), each of which could create and capture value in innovative ventures.

As noted, interest in the business model concept has increased within the mobile service sector [13]. This study departs from the Chesbrough and Rosenbloom [12] framework, since it is comprehensive, generic, and forms part of the open innovation paradigm.

\section{Methodology}

The present study is based on a qualitative methodology for studying the relatively unexplored area of business models in the mobile service sector [14]. The case study design adopts a grounded approach [15] and focuses on the level of mobile service business models rather than on the venture level. This implies that ventures may have different business models for different services provided to customers.

Judgment sampling was used when selecting the case based on the main criterion of entrepreneurs with experience of multiple business models in the mobile service sector. Eleven entrepreneurs were selected as a sample in accordance as suggested by Eisenhart (1989) [16]. Each entrepreneur selected business models with which he or she had experience, resulting in discussions of 4 - 9 business models with each entrepreneur, and a total of 69 business models.

Data was collected through semi-structured interviews with the 11 entrepreneurs exploring key mechanisms in business model design at work and the underlying business model components in the 69 business models. Each interview lasted an average of 90 minutes. The interview guide allowed the researchers to follow up on issues raised during the course of the interviews where those issues of business models were explored with the entrepreneurs. When coding the 69 business models, a multidisciplinary group of researchers first coded individually and then discussed the individual coding in the research group. The group coded each entrepreneur's business models and had frequent meetings comparing the individual researcher's coding. In this process, we observed a very high consistency which may support the internal validity of the research [17]. In a following sequence, we grouped the coding into categories. As a result we identified two main types of business models: demanding and simple.

Simple business models have low internal and external complexity in technology, products and organizational structure. Demanding business models, in contrast, are characterized by high internal and external complexity. We focus on the simple business models as our analyses outline mobile applications exploited through mobile service platforms such as iPhone and Android, all of which have simple business models and the mobile platforms have opened up the mobile service market, market structure provides new logics for business endeavours. In order to explore mobile platform application business models, we present evidence from the representative case of a simple business model. The selected case also represents a business model design in the early phases of the smartphone era. The focus on one illustrative case enabled provision of selected primary data, as well as contextual material necessary to understand the business model de- 
sign at work in the mobile application context. The selected business model case was closely and longitudinally studied for a year from the establishment of the venture.

The study of the illustrative case included six interviews conducted by the team of researchers resulting in an additional 15 hours of transcribed interviews. In this second sequence of in-depth case analysis, the group of researchers independently coded and matched the coding within the group. Central key mechanisms, aspects and themes were identified based on an interpretive process of continuous iteration between the theoretical concepts and empirical patterns [18]. Chesbrough's functions of a business model (see Table 1) constituted the conceptual basis for data analysis. We view in this study the value chain as encompassing internal functions, while the value network is regarded as external to the venture. The function "competitive strategy" was not analyzed due to that the discussions were focused on specific applications and the interviewees did not raise the issue of competitive strategy.

Through the iterative analysis of theoretical concepts and empirical patterns, we used investigator triangulation, which addresses the study's construct validity [14]. We also employed data triangulations by using multiple sources of data such as repeated screenshots of the list of the top 100 downloads in the iTunes App Store and written feedback from the application's customers, as complements to the interviews. Such feedback had been written by people who had purchased/downloaded applications from the iTunes App Store and was then explored through a content analysis. The written feedback received during the first few days after the launch of the studied application, was provided to the researchers. After excluding texts written in languages other than English, 58 pieces of feedback from customers in 11 countries remained. The texts were analyzed with Leximancer software, which simultaneously conducts thematic and relational analysis [19].

\section{The Mobile Application Business Model}

The illustrative case of the mobile application business model is presented as a narrative in the following section.

\subsection{An Application on the List of the Top 100 Downloads-The App Store Case}

In this section, we identify and explore the functions of a business model for a mobile application, which centres on the business model design attached to an innovation process of an iPhone application. The idea of a mobile application originated in a brainstorming session in which the entrepreneur and a developer at the IT venture decided to develop an iPhone application. The mobile service application innovation was outside the scope of the ITventure's ordinary consulting activity. The iPhone platform chosen because of the phone itself combined with Apple's external distribution channel, the iTunes App Store. This was a new market and technology window of opportunity. The entrepreneur believed that the iPhone and App Store offered a unique package of distribution channels and billing in a single system. The entrepreneur and the developer became particularly interested in the 3-axis accelerometer. Their specific competences, limited time and financial resources determined their plan to develop a high complex application.

From idea to release of the application as freeware on the App Store in fall 2008, the process required two weeks. Initially, the ambition was to achieve 5,000 downloads. Three days after launch, however, 100,000 customers had downloaded the application, and it reached top ranking after approximately 200,000 downloads. Given the massive customer response, a new version of the application, for which they charged $\$ 1$, was released two weeks later. The venture team was unsure of the pricing in the structured revenue model at the App Store and whether they could charge existing customers for the second version.

Table 1. Functions of a business model.

1. Articulate the value proposition; i.e., the value created for users by the offering.

2. Identify a market segment; i.e., the users to whom the offering is useful and for what purpose.

3. Define the structure of the value chain required by the venture to create and distribute the offering,

and determine the complementary assets needed to support the venture's position in this chain.

4. Specify the revenue generation mechanism (s) for the venture, and estimate the cost structure and

profit potential of producing the offering, given the value proposition and value chain structure chosen.

5. Describe the position of the venture within the value network linking suppliers and

customers, including identification of potential complementors and competitors.

6. Formulate the competitive strategy by which the innovating venture will gain and hold advantage over rivals. 
At this point, downloads dropped dramatically, perhaps because of the pricing structure. An additional factor was that customers of the second version erroneously received the first version due to a problem with the App Store, and they were unwilling to pay for an application that had been free. Moreover, when the first customers tried to download the second version, they were informed that they already had the latest release. Customer feedback included some complaints, and the application dropped in ranking on the App Store's list. However, a second App Store bug balanced the first somewhat, since the number of downloads as a free application followed the application as it entered the list for paid applications. Therefore, the application re-entered the top list, though only briefly.

After two weeks, the application had dropped from the top but still received approximately 200 downloads daily, peaking on weekends. At that time, it was uncertain whether a third version would be launched since this would require competences not available internally in the existing IT-venture. Nevertheless, the entrepreneur and the developer formalized their new business based on the mobile application into a new venture in order to manage all the transactions linked to the application.

Figure 1, based on data collected through repeated screen shots of the list of the top 100 downloads in the iTunes App Store, shows the application's place. The first observation (day 1 in the figure) was made 1.5 weeks after the application was launched, just before the venture started to charge for the mobile service application.

\subsection{Business Model Component Design at Work}

The case of business model design is conceptually elaborated using Chesbrough's functions of a business model.

\subsubsection{Value Chain}

The new venture's primary focus in the value chain was on product development. The entrepreneur was a business manager with experience from different start-ups and from managing ventures while the developer was a selftaught programmer/developer. However, the venture team did not have any previous experience with mobile service applications and innovation in that format and therefore relied on their social network as complementary resources and sources of information during the innovation process.

The network used in the innovation process, based on the entrepreneur's personal network of former colleagues and friends, was rich and diverse in terms of competence relevant for the business model design in the new venture. This was especially valuable since iPhone applications require short innovation processes and since the team's development had an ad-hoc character, where problems were solved as they arose. In these circumstances, the entrepreneur thought that it was impossible to establish "formal" contacts (based on contracts and other mechanisms) and build a new social network tailored to this type of service. Further, the entrepreneur's personal contacts were based on trust and mutual exchange rather than financial transactions. This was important since the venture team had scarce financial resources.

\subsubsection{Value Proposition}

The mobile service application was developed with a focus on the iPhone technology, the venture team's competences, and its desire for innovating an entertaining mobile service application. At the innovation stage, no customer interaction was conducted. Still, customer responses

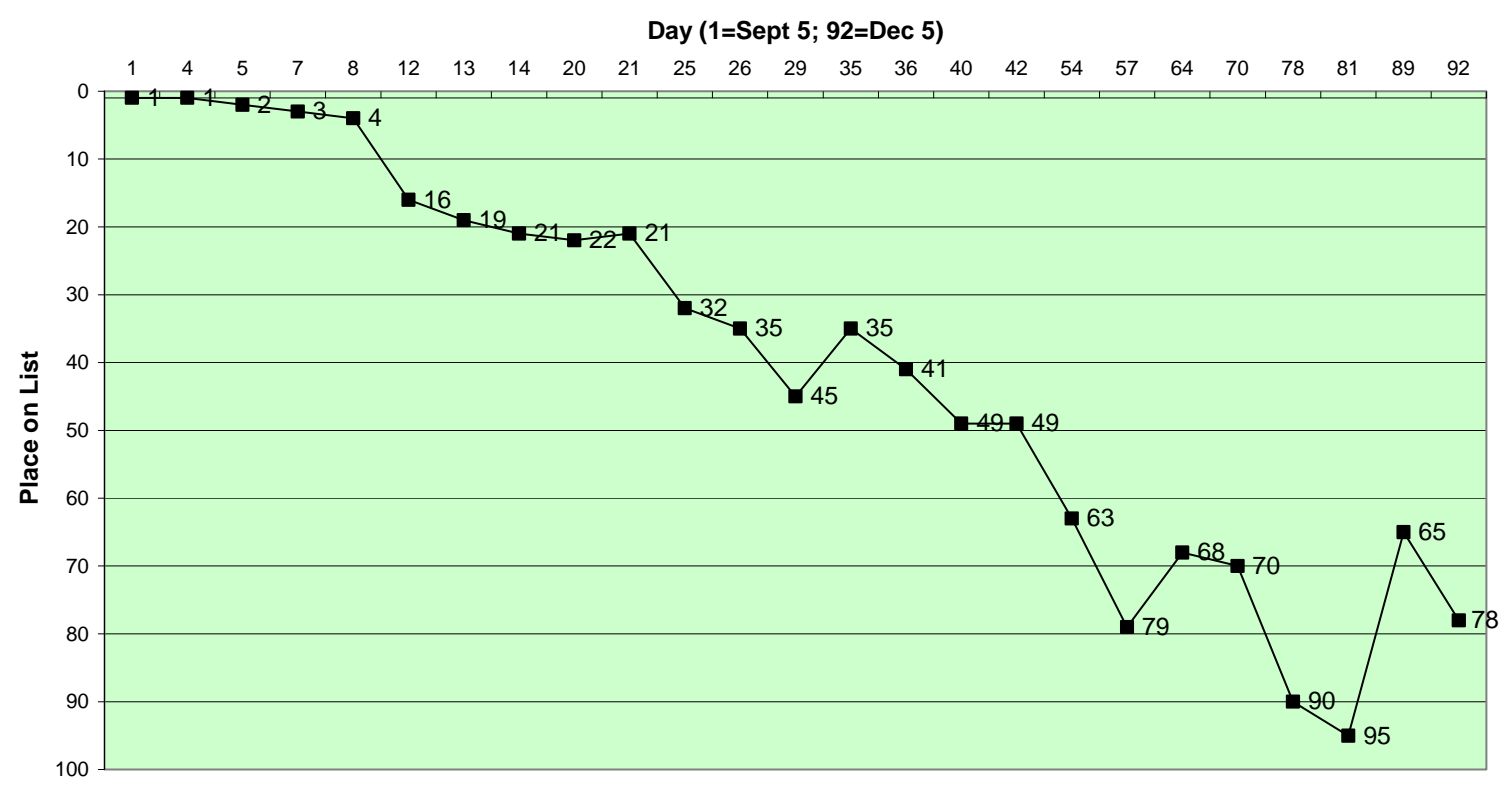

Figure 1. The mobile service application's place on App Store's top 100 list. 
revealed unmet customer needs. After the release of the mobile service application, the venture team began to receive written customer feedback concerning the application (in App Store reviews and e-mails), including suggestions for new features and illustrations of different use situations.

Results of the content analysis indicate that beyond general comments, such as the application being "fun" or "cool”, two major themes existed in the customers' reviews: the inability to save results, and the application's high sensitivity in utilizing the accelerometer.

The entrepreneur perceived customer feedback as very important in refining the application, planning new releases, and building trust with customers. The venture team also responded to all e-mails from customers. However, the venture team quickly decided to focus on innovations that would appeal to a large part of the target group without requiring significant financial and human resources. Hence, to keep technology and business complexity low, the entrepreneur chose to have a single product aimed at a single target group. The choice not to develop relationships with customers or promise them new features by request was made for the same reason.

\subsubsection{Market Segment}

Instead of starting with a focus on selecting relevant customer groups, the venture team first selected from among different mobile service platforms (iPhone, Nokia, Android). The team viewed the iPhone as a choice of a particular market window. It was not possible for the venture team to direct a mobile service application to any one market segment through the App Store distribution channel, which meant that the market segment had to involve all iPhone customers. Next, a gap in the supply of iPhone applications was found relative to the 3-axis accelerometer technology.

Rather than pointing to specific customer segments, the entrepreneur therefore stated that to succeed in the market it was essential to identify opportunities within the new technology and the market window available. Being first or second with a new type of application was regarded as a crucial race since they suspected that other entrepreneurs would soon release similar services. This actually happened during the period of study, when a very similar application-essentially a copy-appeared in the App Store. The entrepreneur assumed that this copycat venture had the financial resources to back up its business and the entrepreneur already lost market shares to the copycat.

The entrepreneur also noted the importance of making an application visible in an overcrowded and constantly growing market. In its first nine months of operation, Apple reported one billion App Store downloads and a total availability of more than 35,000 apps [20]. There- fore, being highly ranked on the top lists in order to achieve visibility and gain the attention of potential customers was crucial to the venture team. The entrepreneur also viewed traditional word-of-mouth as an important promotional channel, and as an explanation for the application's weekend download peaks. Moreover, six months after the application's launch, it emerged at the torrenttracker site Pirate Bay. Far from being annoyed by the illegal file sharing of the product, the entrepreneur viewed it as a free promotional channel that would perpetuate use of the application and lead to additional paid downloads.

\subsubsection{Revenue, Cost, and Profit}

Estimating the cost structure and profit potential was not a priority for the venture team. Rather, the entrepreneur handled such issues as they appeared in the distribution process set by Apple. The venture team did not invest significant financial or other resources in innovation; instead, it stretched its scarce financial resources and used capital from the entrepreneur's other IT-venture to finance the application innovation work.

Since the venture team prioritized quick visibility over potential profit, it started by releasing the application as freeware on the App Store. The second version of the application was priced low in the expectation that the potential customer segment was price-sensitive. However, the venture team was unfamiliar with the regulations concerning App Store's revenue model. Thus, the entrepreneur was surprised to learn that upgrades to an application are free for previous customers. This meant that they could only charge new customers; thus, purchasers of the first version received the second upgraded version for free. Eventually, the entrepreneur felt that they had established a number of customer relationships in the market and the entrepreneur expected them to recommend the application to their acquaintances. Such promotions were prognosticated to generate approximately five new downloads per day in the long term. The entrepreneur weighed the pro and cons at the end of the current study and stated that it would be easier initially to exploit the application on the market with a free application, but for achieving sustainability, the ventures costs must be covered, and thus the application must be sold. Therefore the revenue logic of such distribution channels as the App Store needs to be considered in the initial business model design.

\subsubsection{Value Network}

By choosing the App Store as the platform for the venture team's entrepreneurial mobile service endeavours, most of the functions in the value network become regulated. Entrepreneurs of mobile applications associated with the iPhone are limited to the position in the value network to the innovation process of the service since the distribu- 
tion channel and billing system are predetermined, regulated, and owned by Apple. Hence, it is impossible for the entrepreneur to control these positions. Apple may according to the entrepreneur be seen as a third party providing an open innovation platform (i.e. a market channel for distribution of mobile service applications).

Based on the venture's predetermined positions in the value network, the venture team was unable to perform marketing activities, such as writing press releases or providing other information related to its mobile service application. The application distributors in the App Store community were not even allowed to share or communicate business information related to their application, such as sales figures and its position on the top lists, with outsiders. However, the venture team maintained ownership of the idea and the mobile service application. Related to this, the entrepreneur suggested that Apple should be more active in solving the copycat problem. Even if the individual venture has the legal right to take legal action against copycats, the venture lacked the financial resources to engage in such processes when copycats were discovered.

Another delimiting effect of the App Store platform, according to the entrepreneur, was the restricted opportunity for collaboration with other entrepreneurs in the App Store. The entrepreneur believed that by restricting collaboration, Apple could control developers' business endeavours.

\subsubsection{Extending Chesbrough's Business Model}

Two key mechanisms that were excluded from Chesbrough's conceptual business model functions are identified as central to the business model design in open innovation: contingency aspects and core resources. The contingency aspects are pace of change and regulatory constraints. Pace of change covers technology development and sector characteristics. The sector characteristics are in flux. More specifically, there is no dominant standard among mobile services, and small ventures are unaware of revenue flows in the sector and their effect on business performance. This was also evident in the illustrative case. Thus, the sector is young, evolving, rapidly changing, and thus characterized by high business and financial risks. Parallel to this, visibility in the market place is becoming increasingly difficult since a rapidly growing number of mobile service applications (in App Store and elsewhere) compete in the market. Technology development is characterized by short product development cycles and short life cycles in the market, both of which call for swift decision-making in innovation and distribution processes.

In terms of regulatory constraints, Apple exercises strict control over entrepreneurs by clearly defining boundaries for what they must and cannot do in terms of cooperation with other entrepreneurs and being visible through ex- ternal communication of their product. The App Store regulates the majority of roles, responsibilities, and activities associated with the business aspects of mobile service applications.

The key mechanism of contingency aspects also influences the core resources, which include human, financial and social resources. Regarding human resources, the entrepreneur claimed that in order to develop the business model by releasing an advanced version of the application, front edge competence in programming, for example, would be required, and this was outside the venture team's competence. This pinpoints the importance of human resources in the business model design.

Regarding financial resources, most mobile service applications are characterized by uncertain payback, which is why making significant investments of financial resources in the business model design is risky. In addition, entering a venture capital due diligence process for accessing financial resources is time consuming and difficult to match with the industry's rapid evolution. This is evident in our illustrative case where the venture team was contacted by a potential financier who saw an investment opportunity. However, because of the rapid changes in the sector and the need for quick innovation and decision processes, the venture team was too focused on the business model design and was not able to respond to the offer in time. To compensate for the scarce financial resources, the entrepreneur used his social networks that enabled the venture team to manage without financial resources in value creation. The entrepreneur's social network contributed expertise and advice instead of financial resources. In addition, the short development cycles in the sector made the use of existing social networks significant, since the venture team lacked the time to improve its own competence. Accordingly, social resources may substitute for the lack of financial and human resources. This highlights the importance of social resources in business model design.

\section{A Model for Business Model Design at Work}

We propose a model for business model design (Figure 2) in the open innovation context of mobile service applications and thus for those simple business models attached to mobile platforms such as the App Store. We thereby contribute to the earlier frameworks on business models by incorporating the key mechanisms: contingency aspects and core resources into business model design. The contingency aspects and the core resources interact with the business model components. In designing sustainable business models, it is essential to manage its components, contingency aspects, core resources, and their interconnections. 


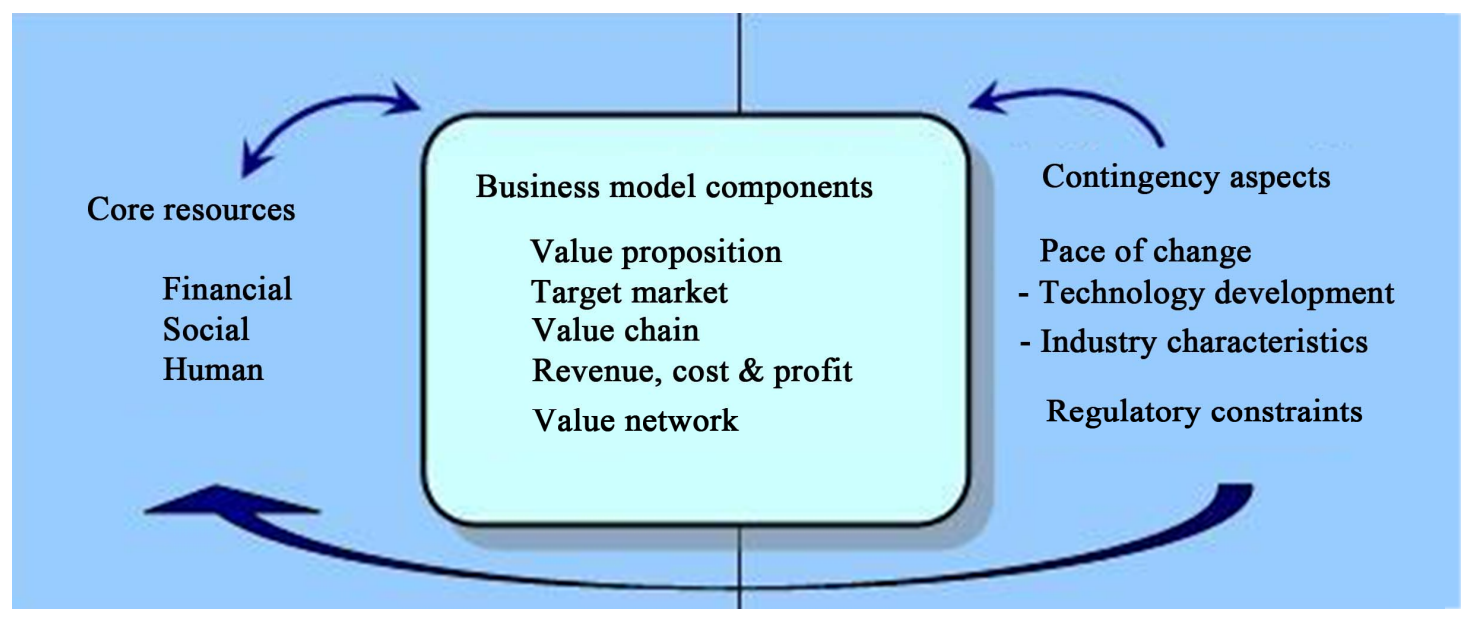

Figure 2. Business model design at work.

Two contingency aspects are proposed in the model: 1) pace of change regarding technology development and sector characteristics; and 2) regulatory constraints. The mobile service sector is fragmented and lacks established structures and norms while mobile platforms such as App Store are highly regulated. The mobile service sector is also characterized by discontinuity in technological change, a high degree of technical uncertainty driven by highly complex technological systems, short product development-to-market cycle times, and short product life cycles. Parallel to this, the mobile platforms enable entrepreneurs to deal with the high uncertainty and complexity and simplify the business model design so that it requires less effort from the entrepreneurs to reach their market. However, the mobile platforms also make it difficult for entrepreneurs to explore their business model potential since they must co-operate with others in the platform and visibly market themselves through other market channels.

The number of competitors increases rapidly as ventures identify opportunities in the market, as argued by Jones et al. [21]. The platform enables entrepreneurs to exploit their mobile services through a well recognized and legitimate market place while the entrepreneurs' services risk being lost among the myriad others in the marketplace.

Human, financial and social resources are important for designing a sustainable business model in an open innovation context. Ventures with a working business model design tend to mobilize support in their social networks to compensate for shortcomings in human and financial resources [22]. Accordingly, access to social network may constitute a substitution mechanism when there are shortcomings in human or financial resources [23]. Using social networks to compensate for financial constraints, known as bootstrap finance, is extensively applied in new ventures [24] and thus a central part of the business model design. Our model suggests that entrepreneurs who have experience with similar business model designs bring relevant competence and social relationships to business opportunities [25]. Bringing such resources into the design of a business model significantly reduces the liability of newness, which is especially important when the pace of change is fast and regulatory constraints are severe. Accordingly, the business model design will fast be up and running and the risks of building in business model flaws in the design from the very beginning diminish with entrepreneurs having prior experiences.

Financial constraints in a model design pinpoint the importance of access to adequate financial resources in order to exploit the business model potential and become sustainable. Cash-strapped start-up ventures in an open innovation context may face significant difficulties since they may be unable to respond promptly to customer needs [26]. Such ventures are likely to be out-innovated by financially stronger ventures. While human, social, and financial resources are seen to influence all components of the business model, the relationship is reciprocal as decisions regarding components define what type and amount of resources will be required. Further, the contingency aspects' pace of change and regulatory constraints are considered as overarching mechanisms influencing the composition of both business model components and core resources in the business model design in an open innovation context.

\section{Conclusions}

Our findings indicate a need for continually designing and managing business models in the open innovation context of the mobile service sector for reaching sustainability. Understanding, designing, and managing business models at work offer opportunities to thrive in these relatively new and rapidly evolving sectors. Many researchers emphasize the importance of business models; however, it is not simply meeting the challenge to put together a logic 
of business model components; a business model can be more or less sound and coherent, it may not necessarily and still fail to address the full business potential and become sustainable. The subsequent challenge is to manage the business model design at work and incorporate the key mechanisms. To illustrate the impact of recent trends of open innovation in services and attached business models, we propose a model for managing a business model design. The model extends earlier frameworks by incorporating the key mechanisms; contingency aspects and core resources to manage the business model components in the dynamic mobile service sector.

The findings from the study highlight the importance for ventures in the mobile service sector to manage the business model design at work and to incorporate core resources and contingency aspects to support the sustainability of their business models. This article's contribution to the literature on business models consists of a model that supports Chesbrough and Rosenbloom's business model framework. An open innovation context seems to require business models adapted to the mobile service sector's logics of contingency aspects. Identifying the logics in specific sectors has allowed for theoretical considerations of the different types and effects of, for example, environmental complexity [27]. The contingency logics of mobile service applications attached to the App Store context involves high risks of losing market shares to copycats that have the resources to develop new releases of the copied application. This indicates the importance of incorporating such issues into the business model design. Such copycat risks are significant in open innovation contexts. Further, the business model design attached to mobile platforms both enables launching innovations to a global market through a highly regulated distribution channel that still offers flexibility in individual ventures innovations endeavours but limit opportunities to co-operate with other ventures attached to the platform. The advantage of being born global via using a mobile service platform, such as App Store, is minimal effort required in the business model design regarding distribution channels when launching innovation. The findings suggest that mobile service applications have great potentials of being born global despite restricted financial resources. The findings also indicate that social networks may be central in compensating for shortfalls in financial and human resources. This involves both structuring and management of the resource stocks and flows. Managing the logics of mobile service platforms makes a business model design possible, and thus enables the revenue model to fit the logic in order to ensure financial stocks and flow in a timely manner, including gaining access to sufficient financial resources for the business model design to become sustainable.

We contribute to the service science literature by pro- posing a model to advance the management of business model design in the mobile service sector. We provide guidance for practitioners on management of business model design in the mobile service sector and particularly for those operating in an open innovation context and attached to mobile service platforms.

We realize that our work has limitations. We recognize a need for further studies in the field of management of business model design. As such, we encourage future researchers to test the model and the findings from this study. This would help to assess the reliability and validity of the results and to extend our knowledge of business model design at work. We encourage future researchers to incorporate other mobile service platforms, since the structural logics attached to specific platforms may have different effects on the constraints of business model design and how it can be managed.

\section{REFERENCES}

[1] A. Jantunen, N. Nummela, K. Puumalainen and S. Saarenketo, "Strategic Orientations of Born Globals-Do They Really Matter?” Journal of World Business, Vol. 43, No. 2, 2008, pp. 158-170. doi:10.1016/j.jwb.2007.11.015

[2] A. Osterwalder and Y. Pigneur, "An Ontology for EBusiness Models,” In W. Currie, Ed., Value Creation from E-Business Models, Butterworth-Heinemann, Oxford, 2004, pp. 65-97.

[3] H. Chesbrough, "Business Model Innovation: It's Not Just about Technology Anymore,” Strategy \& Leadership, Vol. 35, No. 6, 2007, pp. 12-17. doi:10.1108/10878570710833714

[4] T. F. Stafford and M. L. Gillenson, "Mobile Commerce: What It Is and What It Could Be,” Communications of the ACM, Vol. 46, No. 12, 2003, pp. 35-40. doi:10.1145/953460.953483

[5] C. A. Looney, L. M. Jessup and J. S. Valacich, "Emerging Business Models for Mobile Brokerage Services," Communications of the ACM, Vol. 47, No. 6, 2004, pp. 71-77. doi:10.1145/990680.990683

[6] H. Chesbrough, “The Era of Open Innovation,” MIT Sloan Management Review, Vol. 44, No. 3, 2003, pp. 35-41.

[7] V. Nedimovic, "The Trends of Open Innovation in Services,” European Commission, Information Society and Media Directorate General, 2009. http://ec.europa.eu/information_society

[8] M. Morris, M. Schindehutte and J. Allen, "The Entrepreneur's Business Model: toward a Unified Perspective," Journal of Business Research, Vol. 58, No. 6, 2005, pp. 726-735. doi:10.1016/j.jbusres.2003.11.001

[9] A. Osterwalder, Y. Pigneur and C.L.Tucci, "Clarifying Business Models: Origins, Present, and Future of the Concept." Communications of the Association for Information Systems, Vol. 16, No. 1, 2005, pp. 1-25.

[10] S. M. Shafer, H. J. Smith and J. C. Linder, "The Power of Business Models,” Business Horizons, Vol. 48, No. 3, 2005, pp. 199-207.doi:10.1016/j.bushor.2004.10.014 
[11] M. Morris, M. Schindehutte and J. Allen, "The Entrepreneur's Business Model: toward a Unified Perspective," Journal of Business Research, Vol. 58, No. 6, 2005, pp. 726-735. doi:10.1016/j.jbusres.2003.11.001

[12] H. Chesbrough and R. S.Rosenbloom, "The Role of the Business Model in Capturing Value from Innovation: Evidence from Xerox Corporation's Technology Spin-Off Companies,” Industrial and Corporate Change, Vol. 11, No. 3, 2002, pp. 529-555. doi:10.1093/icc/11.3.529

[13] G. Camponovo and Y. Pigneur, "Business Model Analysis Applied to Mobile Business," The 5th International Conference on Enterprise Information Systems, Angers, 23-26 April, 2003, pp. 173-183.

[14] R. K. Yin, "Case Study Research: Design and Methods," 3rd Edition, Sage Publications Inc., Thousand Oaks, 2003.

[15] B. G. Glaser and A. L. Strauss, "The Discovery of Grounded Theory: Strategies for Qualitative Research,” Aldine Transaction, London, 1967.

[16] K. M. Eisenhardt, "Building Theories from Case Study Research," Academy of Management Review, Vol. 14, No. 4, 1989, pp. 532-550.

[17] M. Gibbert, W. Ruigrok and B. Wicki, "Research Notes and Commentaries: What Passes as a Rigorous Case Study," Strategic Management Journal, Vol. 29, No. 13, 2008, pp. 1465-1474. doi:10.1002/smj.722

[18] I. Kerssens-van Drongelen, "The Iterative Theory-Building Process: Rationale, Principles and Evaluation,” Management Decision, Vol. 39, No. 7, 2001, pp. 503-512. doi:10.1108/EUM0000000005799

[19] A. D. P. Sweeney, "Electronic Government-Citizen Relationships: Exploring Citizen Perspectives,” Journal of Information Technology \& Politics, Vol. 4, No. 2, 2007, pp. 101-116. doi:10.1080/19331680802076165

[20] http://www.apple.com/pr/library/2009/04/24appstore.html ?sr=hotnews

[21] G. K. Jones, J. R. A. Lanctot and H. J. Teegen, "Determinants and Performance Impacts of External Technology Acquisition,” Journal of Business Venturing, Vol. 16, No. 3, 2000, pp. 255-283. doi:10.1016/S0883-9026(99)00048-8

[22] J. Brüerl and P. Preisendörfer, "Network Support and the Success of Newly Founded Businesses," Small Business Economics, Vol. 10, No. 3, 1998, pp. 213-225. doi:10.1023/A:1007997102930

[23] B. Honig, "What Determines Success? Examining the Human, Financial, and Social Capital of Jamaican Microentrepreneurs,” Journal of Business Venturing, Vol. 13, No. 6, 1998, pp. 371-394. doi:10.1016/S0883-9026(97)00036-0

[24] J. Winborg and H. Landstrom, "Financial Bootstrapping in Small Businesses: Examining Small Business Managers' Resource Acquisition Behaviours," Journal of Business Venturing, Vol. 16, No. 3, 2001. pp. 235-254. doi:10.1016/S0883-9026(99)00055-5

[25] A. C. Cooper, F. J. Gimeno-Gascon and C. Woo, "Initial Human and Financial Capital as Predictors of New Venture Performance,” Journal of Business Venturing, Vol. 9, No. 5, 1994, pp. 371-395. doi:10.1016/0883-9026(94)90013-2

[26] C. L. Lee, K. Lee and J. M. Pennings, "Internal Capabilities, External Networks, and Performance: A Study on Technology-Based Ventures,” Strategic Management Journal, Vol. 22, No. 6-7, 2001, pp. 615-640. doi:10.1002/smj.181

[27] H. Tosi, “The Environment/Organization/Person Contingency Model: A Meso Approach to the Study of Organizations,” Jai Press Inc., London, 1992. 